\title{
Educação Física Escolar: discutindo a questão das práticas inovadoras
}

http://dx.doi.org/10.11606/1807-5509201800010141

\author{
Uirá De Siqueira FARIAS ${ }^{*, * *}$ \\ Graciele Massoli RODRIGUES ${ }^{* * * * * * * *}$ \\ Walter Roberto CORREIA ${ }^{* * * * *}$
}

* Secretaria Municipal

da Educação

de Santo André,

Prefeitura de Santo

André, Santo André,

SP, Brasil.

** Prefeitura de São

Paulo, São Paulo, SP

Brasil.

*** Universidade São

Judas, São Paulo, SP,

Brasil.

${ }^{\star * \star \star}$ Escola Superior

de Educação Física

de Jundiaí, Jundiaí,

SP, Brasil.

${ }_{* * \star \star \star}$ Escola de

Educação Física e

Esporte, Universidade

de São Paulo, São

Paulo, SP, Brasil.

\section{Resumo}

0 presente ensaio tem por propósito efetuar uma problematização em relação a noção "prática inovadora em Educação Física Escolar". A partir de uma pesquisa bibliográfica, procurou-se analisar a polissemia emergente do termo e, sobretudo, suas implicações para elaboração dos saberes docentes e da própria identidade do componente curricular.

Palavras-chave: Educação Física escolar; Currículo; Didática.

\section{Introdução}

O objetivo do presente ensaio é problematizar a noçáo de práticas pedagógicas inovadoras na Educação Física Escolar, a partir da exploração e análise da literatura especializada. Os anúncios relativos às práticas pedagógicas inovadoras, renovadoras ou "bem-sucedidas" em Educação Física Escolar, vêm sendo veiculados em diversos cenários acadêmicos e, recorrentemente, em muitos contextos escolares. Alavancadas pelo movimento renovador dos anos oitenta do século passado ${ }^{1}$, tais práticas vêm tentando superar o tecnicismo reducionista do modelo esportivizante de outrora, e segue em direção a uma vertente crítica e plural da cultura corporal do movimento ${ }^{2}$. No entanto, em que se admita essa tendência, é imperativo reconhecer que novidades pedagógicas não geram necessariamente inovaçóes educacionais. Não é incomum o anúncio de "modernidades" ou "modismos" no campo educacional, sobretudo, quando temos um pujante apelo mercadológico que, segundo SiLva ${ }^{3}$, contém valores fortemente alicerçados nas ideias de competitividade e preparo para o mercado de trabalho.

O debate sobre as práticas inovadoras está sendo assimilado como um relevante objeto de estudo, sendo problematizado por diferentes marcos teóricos e atores, como por exemplo, Bracht ${ }^{4}$, Carlan, KunZ e Fensterseifer ${ }^{5}$, Faria et al. ${ }^{6}$, GonZÁlez $^{7}$, Silva e BraChT $^{2}$, e mais recentemente, AlmeIda ${ }^{8}$, Farias, Nogueira e Maldonado9. Segundo Correia ${ }^{10}$, a Educação Física Escolar está inserida num contexto de mudanças e evoluçōes historicamente situadas, de forma a identificarmos uma pluralidade de concepções educacionais, perspectivas de análise multidisciplinares, protagonismos diversos e esforços de inovação curricular. Em suma, uma teia de complexidades. No entanto, é preciso questionar qual é o direcionamento desses esforços, especialmente, do ponto de vista da sistematização do conhecimento e da eficácia social dos conteúdos. 
Ainda no tocante ao escopo das mudanças, para $\mathrm{VAGO}^{11}$, as práticas na Educação Física Escolar devem ser orientadas pela invenção e reinvenção pedagógica, fruto de uma interaçâo dinâmica entre os sujeitos das cenas educativas. Comumente, toda e qualquer prática por estar alicerçada em um ambiente escolar marcado pela diversidade humana terá, inexoravelmente, um campo de tensóes inerentes às diferenças culturais dos atores que compóem uma determinada realidade social. As relaçôes entre professores e alunos são permeadas de tensōes e contradiçóes, exigindo, por sua vez, um processo permanente de comunicação e negociação dos sentidos e significados das práticas ${ }^{12}$. A consonância entre a perspectiva docente e discente é um desafio premente na perspectiva da qualidade do ensino e da aprendizagem. A dissonância entre o corpo docente com o corpo discente é algo inerente ao processo de desenvolvimento humano. Contudo, é por essa e outras razóes que se faz necessário uma dimensão crítica e reflexiva do trabalho docente. Um esforço determinado e criterioso nessa dimensão ultrapassa o ingênuo desejo de trazer "algo novo" para a "aula diferente", ainda que se reconheça a autenticidade e honestidade subjetiva e profissional de quem o propóem.

Uma questão essencial, que urge reconhecimento, diz respeito à dimensão polissêmica e não consensual das mudanças e inovações em educação. Messina ${ }^{13}$ amplifica as discussões acerca do termo inovação, nos oferecendo a seguinte distinção:

Da mesma forma, de acordo com a literatura sobre o tema, podem-se identificar dois componentes que distinguem a inovação: a) a alteração de sentido a respeito da prática corrente; b) o caráter intencional, sistemático e planejado, em oposição às mudanças espontâneas. Também enfatiza-se que atualmente a inovação é algo aberto, capaz de adotar múltiplas formas e significados, associados com o contexto no qual se insere. Destaca-se, igualmente, que a inovação não é um fim em si mesma, mas um meio para transformar os sistemas educacionais $^{13}$ (p. 226).

Outro ponto relevante a ser considerado, é a submissão da noção de inovação aos imperativos da racionalidade instrumental e utilitarista provenientes de setores da produção e da administração, cujos produtos e processos educativos são fortemente formatados por práticas pedagógicas homogeneizadoras. Um contraponto dessa realidade ou propensão seria deslocar, ou até mesmo, subverter, a discussão sobre a inovação na educação, incitando e alimentando, entre professores e alunos, o sentir, o pensar, o agir, o compor, o dizer, o contradizer, o experimentar, o avaliar, enfim, a invenção necessária ${ }^{13}$.

Prosseguindo sobre a questão acima mencionada, Pereira e CÉsAR ${ }^{14}$ asseveram que inovar é o processo de transformaçáo das práticas induzidas pelas variáveis que vão surgindo no caminho; tal mudança nega a tradição, justificando-se na necessidade de adequar as práticas aos sujeitos contemporâneos. Esses mesmos autores trazem à tona o termo abertura, balizado pela situação momentânea dos sujeitos e do sistema para acolher a diversidade da relação interpessoal. Mesmo que a prática possua uma estrutura a priori, o planejamento dessa ação admite os pressupostos do inesperado e da incerteza, especialmente, como concessão para o advir e o emergente, elementos potenciais de um processo pertinente de inovação:

A inovação é um processo mais geral e normalmente usado no sentido de "progresso", mas só acontece se houver abertura dos sujeitos para a adequação do tempo-espaço da prática. A abertura, por sua vez, não implica inovação, mas é o primeiro passo para que peculiaridades do modelo anterior sejam rejeitadas ou reorganizadas em novas formas ${ }^{14}$ (p. 622).

Ainda considerando as múltiplas perspectivas de análises que compóem o debate das práticas inovadoras em Educação Física Escolar, podemos inserir os apontamentos de SiLva e Bracht ${ }^{2}$, cuja contribuição incide no reconhecimento do valor da base empírica das atividades pedagógicas, disponibilizando a seguinte compreensão:

O entendimento é o de que nosso (pré)-conceito (de inovação) deve se abrir ao diálogo com o mundo empírico para que se construa, nesse diálogo, uma compreensão do que pode significar práticas inovadoras. Com isso não estamos advogando estabelecer a tirania do fático ou a primazia do empírico, não estamos, portanto, abrindo mão de confrontar o fático com o contrafático, em suma, com uma determinada concepção de Educação e Educação Física. Estamos procurando apenas evitar operar com uma concepção rígida e idealizada que se sobreponha, que submeta o mundo da vida (o empírico) à uma só forma. Em princípio, poderíamos dizer que estamos interessados em inovaçóes que alteram o sentido da prática e não apenas, acrescentem, por exemplo, conteúdos novos (por exemplo, além dos esportes convencionais como vôlei, basquete, etc. ensinar também os esportes radicais) ${ }^{2}$ (p. 84).

De forma semelhante ao exposto, especialmente no que concerne à necessidade de se resguardar as 
práticas educativas das tentaçóes de rigidez contidas em modelos pré-concebidos, Pereira e CÉsar ${ }^{14}$ reforçam que quando se adota uma pedagogia da abertura, o sistema não fica atrelado às mudanças, ajustamentos e inovaçóes, mas, sim, favorece uma escolha que pode seguir uma direção diferente à que está em vigor, além de proporcionar aos sujeitos envolvidos um sentido ampliado de liberdade que, por sua vez, pode incrementar a envergadura das experiências e suas respectivas marcas de existência ${ }^{13}$. GonzÁlez e Fensterseifer ${ }^{15}$ ressaltam que as intenções inovadoras devem convergir para que as novas geraçóes de alunos e professores possam ter conhecimentos e condiçóes para compreender e atuar na sociedade contemporânea, ou seja, na perspectiva $\mathrm{da}$ aprendizagem significativa e da autonomia.

Ainda sob o prisma das práticas inovadoras, SiLva e BRACHT ${ }^{2}$ enfatizam que a inovação pode derivar de vários entendimentos e conceitos e, quando se pensa em Educação Física e Educação, mais especificamente nas décadas finais do século passado, o conceito parece atender a uma transformação da prática pedagógica no seu caráter político, uma revoluçáo de ordem social. Outros interlocutores sustentam que a maneira como o termo é assimilado no âmbito acadêmico e profissional é passível de muitas ambiguidades e controvérsias semânticas e hermenêuticas, todavia, incluem, invariavelmente, uma expectativa e intencionalidade de mudança dos sentidos das práticas muito além de uma coletânea de práticas diversificadas ${ }^{13}$.

Carlan, Kunz e Fensterseifer ${ }^{5}$ discutindo a temática das práticas inovadoras comentam que pensamento pedagógico renovador da Educação Física impulsionou a produçáo científica da área, mas, amiúde, ainda não seria expressiva o suficiente a ponto de engendrar mudanças significativas nas práticas pedagógicas dos professores, patentemente, no que toca a dimensão crítica das aulas. Nesse sentido, seria oportuno trazer para discussão a incorporação das práticas inovadoras como objeto de investigação acadêmica, dada a relevância da produção de conhecimento para a formação e atuação profissional de professores e professoras de Educação Física, especialmente, as investigaçóes que analisam como os docentes compreendem e fazem uso dessa denominada prática inovadora.

Portanto, do ponto de vista da produçáo de conhecimento, MaLdonado et al. ${ }^{16}$ analisaram a produção nacional de periódicos científicos no período de 1980 a 2015, cujos objetivos e temas tratavam do ensino das manifestaçóes da cultura corporal do movimento em escolas públicas brasileiras. Dentre as revistas analisadas da Educação (20) e da Educação Física (23), foram identificados 161 artigos que tratavam do tema inovação pedagógica. Os referidos autores explicitam que em algumas dessas práticas, os professores se apoiavam em diversas concepçóes metodológicas da Educação Física, muitas vezes ecléticas e, comumente, se ocupavam em considerar as três dimensóes do conteúdo (atitudinal, procedimental e conceitual), além da inserçáo da pauta de gênero no âmbito das suas preocupaçóes e práticas.

Ainda no que tange à produção do conhecimento, com o objetivo de entender as práticas inovadoras, Fensterseifer e Silva ${ }^{17}$ salientam que professores empenham-se em superar certos reducionismos junto às manifestações da cultura corporal, indo além do simples exercitar-se ou mover-se de forma mecânica e estereotipada, denominando suas próprias elaboraçóes como práticas "bem-sucedidas ou inovadoras". Importante sublinhar que não é simplesmente trazer à tona a temática inovação, mas, principalmente, problematizar as práticas inovadoras da Educação Física a partir do contexto escolar. Os professores participantes da investigaçáo levantaram a relevância das formaçóes continuadas, como condicionantes para ampliação e aperfeiçoamento das suas práticas, especialmente, no que se refere à partilha solidária e colaborativa das experiências entre os pares docentes.

De maneira análoga às consideraçôes anteriores, GoNZÁLEZ ${ }^{7}$ reafirma que professores com práticas inovadoras esforçam-se para não abrirem mão da dimensão autoral do seu trabalho, visivelmente, quando utilizam do tempo e espaço escolar para produzir e criar, nutrindo-se, muitas vezes, de pressupostos e inspiraçóes que vem de outras instâncias sociais, outros campos da cultura ou práticas sociais. Não é incomum que as dúvidas e incertezas inexoráveis do trabalho educativo se imponham perante as concepções dos professores e, por essa razão, esses mesmos anseiam por compreensões mais elaboradas sobre as suas escolhas e preferências pedagógicas. A despeito de um comum e pressuposto desprestígio social com a docência, muitos professores tendem a enfrentar tais adversidades buscando reconhecimento a partir da realização do seu trabalho, da sua "poiesis", da sua potência de ser, estar e viver a docência. Uma necessidade legítima de um trabalhador no mundo e com o mundo, que almeja se ver na sua própria obra, em comunhão com outros atores legítimos, como por exemplo, os alunos, funcionários e educadores em geral. Uma luta, não rara, de resistência contra uma renitente alienação imposta. 
Destarte, a questóes relativas às práticas inovadoras em Educação Física Escolar, sejam como objeto de investigação ou prática pedagógica, se inscrevem como demandas sociais legítimas a serem consideradas no campo do currículo escolar. CAPARROZ e BRACHT ${ }^{18}$ questionam, ou até mesmo, reivindicam, o tempo e o lugar da didática na Educação Física, de forma a assinalar a importância da retomada das reflexóes e práticas pedagógicas com vistas a ampliação da autonomia docente perante a sobreposição das determinações acadêmicas e/ou técnicas provenientes das instâncias diversas do sistema educacional. Esses autores propóem uma interlocução dos docentes com os diferentes agentes da educação, todavia, advertem para a necessidade dos professores e professoras assumirem sua autoridade na construção do seu trabalho pedagógico. Nessa direção, advertem que se os docentes empreenderem uma conduta autoral perante o trabalho pedagógico, esses mesmos poderão descobrir que são portadores de soluçôes legítimas para o processo ensino-aprendizagem do que aquelas prescritas pelos manuais técnicos, pelos pesquisadores ou representantes do meio acadêmico:

Ao nos referirmos à autonomia docente entendemos que tal está relacionada com uma perspectiva na qual os professores devem buscar construir e conquistar sua competência didático-pedagógica para desenvolver sua prática pedagógica na complexa trama de relaçôes que engendra o cotidiano escolar de modo que não permita que os professores sejam constantemente (ou até eternamente) reféns tanto dos especialistas/ experts (pesquisadores do âmbito acadêmicouniversitário) que produzem uma literatura acadêmica que se converte em referência que orienta e determina a prática pedagógica na escola, como também das políticas educacionais e as propostas pedagógicas oficiais/ordenamento legal que orientam/normalizam (enrijecem) tal prática. Não estamos de maneira alguma defendendo uma desvinculação/separação entre os professores que atuam no cotidiano escolar e os especialistas e também o Estado, defendemos, sim, é a interação e interlocução, mas sem dependência por parte dos professores em relação àqueles. Os professores devem valer-se de sua autoridade e de sua autoria docentes para buscar sua autonomia, o que significa poder escolher e construir sua prática pedagógica e não apenas aplicar algo elaborado por outros. Se os professores de educaçáo física fizerem esse esforço de exercer sua autoria docente, com autonomia e autoridade, talvez possam descobrir que há muito mais possibilidades de respostas para os problemas da educação física escolar que os manuais, pesquisadores e/ou os professores do âmbito universitário podem dar ${ }^{18}$ (p. 34-35).

Sumarizando um pouco os dados trazidos pela nossa argumentação ensaística, podemos reconhecer que a emergência das denominadas práticas inovadoras em Educação Física Escolar podem ser resultantes do dinamismo e vitalidade de uma área da educação brasileira que advém desde o século dezenove e, historicamente, envida esforços acadêmicos e profissionais para se deslocar da mera e circunscrita presença legal para práticas e açóes legitimadas (qualificadas). As práticas inovadoras não são objetos e realizaçóes exclusivas de um ou outro componente curricular, mas, sim, uma busca incessante de legitimação dos interlocutores e protagonistas da educaçáo de modo geral. Essa alusão se dá, também, pelo reconhecimento de que o currículo é um campo de entrecruzamento de concepçóes de mundo, sociedade e ser humano e, por essa razão, um terreno de disputas políticas e sociais.

Podemos com facilidade identificar o pressuposto dinamismo e desejo institucional da Educação Física Escolar em legitimar seu tempo e espaço na escola brasileira, testemunhando o crescimento vertiginoso de trabalhos apresentados nos periódicos científicos nacionais, seminários e congressos científicos, produçóes e coleçóes bibliográficas, especialmente, aqueles configurados como relatos de experiência, pesquisa ação, estudo de casos, propostas de formação continuada e práticas denominadas alternativas ou inovadoras. Nesse âmbito, um enaltecimento valorativo do conhecimento empírico, do protagonismo docente, da autonomia docente, da dimensão reflexiva sobre a práxis docente etc. Nesse contexto, também, valem as ressalvas de que no seio da noção de práticas inovadoras, estão entremeados conteúdos e expectativas utilitárias, reducionistas e valores economicistas timbrados pelas denominaçóes ordinárias e efêmeras do tipo "práticas modernas", "inovadoras" e "eficazes". Nesse sentido, vale o reforço de que a linguagem em educação não é desinvestida de intencionalidades, não é inocente, conforme assinalam SACRISTAN et al. ${ }^{12}$ :

As linguagens que versam sobre a educação expressam a diversidade de formas de entendê-la, avaliá-la e colocá-la a serviço de necessidades nem sempre coincidentes. As diferentes visóes sobre o que, o como e o para que de uma educação nutrem a dialética sobre ela, que deve ter determinados 
rumos nas sociedades democráticas. Nas que não são, a visão que triunfa é aquela que impóe o poder, às vezes camuflado nas linguagens. Por isso, a primeira condição da educação democrática é a de reconhecer que pode ser entendida por meio de diferentes discursos, com validade desigual entre eles mesmo com pesos distintos ${ }^{12}$ (p. 16).

Essa perspicaz reflexão vale para a maneira com que o ideário das práticas inovadoras é assimilado, defendido, veiculado e legitimado. Seja no domínio acadêmico ou no profissional, os ensejos subjacentes das práticas pedagógicas nem sempre são coincidentes e, habitualmente, são amalgamados sob a forma de "slogans". Slogans são recursos de linguagens muito utilizados para impulsionar ou validar algumas ideias ou marcas, mas igualmente, podem se prestar para obter consensos, encerrar discussão, acobertar as insuficiências argumentativas ou, até mesmo, acobertar as finalidades corporativas ou políticas que não se convém explicitar. Mediante importantes conceitos como qualidade de ensino, ensino democrático, abordagem crítica, autonomia docente e, no que tange ao objeto do presente ensaio, práticas inovadoras, é essencial a vigilância epistemológica para que ideais ou noçóes fundamentais não se esvaziem nas dobraduras das linguagens astutas do tipo slogans.

Para tanto, sem embargo, é ajuizada a admissão de que dispomos de um cenário significativamente marcado por experimentações pedagógicas legítimas, pesquisas dotadas de diversificação e pertinência epistemológica para Educação Física Escolar, ensaios didáticos e curriculares etc. Entretanto, talvez seja oportuno para o desenlace dessa pretensa análise, considerar mais um contraponto, ou seja, para onde apontam as práticas inovadoras? Que outras questóes estão encerradas na efervescência das suas manifestaçóes? Que critérios as inciativas críticas e propositivas em Educação Física Escolar deveriam ponderar para que não caiamos em voluntarismos ou personalismos episódicos e contingências para a sustentabilidade curricular da Educação Física na Escola?

Como proposição hipotética, longe de exaurirmos a questão no presente texto, asseveramos que um fator importante diz respeito à dificuldade em estabelecer mais criteriosamente os limites da especificidade do componente curricular. Possivelmente, um fator que perpassa a premência da eclosão de açôes inovadoras pode guardar relaçóes com a dificuldade histórica de dar contorno ao objeto de ensino e aprendizagem na Educação Física Escolar. A discussão sobre qual é a identidade da área na escolarização vem sendo uma questão de longa data.

A título de exemplificação, nos anos noventa do século passado, alguns interlocutores questionavam se a Educação Física Escolar se constituía como um autêntico componente curricular ou se circunscrevia como uma atividade curricular. A ideia de componente presume que o mesmo comporta algo peculiar, como por exemplo, conteúdos provedores de distinção e identidade claramente definida. TANI ${ }^{19}$ indagou as razóes que nos levam a insistir em convencer as pessoas e a sociedade de que a Educação Física escolar é importante e se justifica na escola. Sua conclusão é de que acadêmicos e profissionais não tem clareza da sua própria identidade, daí, portanto, a motivação das insistências. Nessa mesma direção, outro posicionamento digno de nota, diz respeito a uma analogia feita por MAriz de Oliveira ${ }^{20}$, quando o mesmo comparou a Educação Física a um "castelo de areia" numa "praia" denominada escola. $\mathrm{Na}$ perspectiva do autor dessa metáfora, a escola contém muitos "castelos" que representariam as diferentes disciplinas, cuja consistência e resistência às marés dependeria, fundamentalmente, da "liga", ou seja, da coerência interna da mesma compartilhada pelos seus atores:

Não resta dúvida que muitos têm trabalhado com seriedade nessa missão de construção desse castelo, mas tenho notado que falta a essência de uma liga consistente que possa manter o castelo em pé, independente de diferentes formas de acabamento, decoração e retoques indispensáveis e necessários. Assim, tenho visto esforços de diversos colegas, de vários grupos, falando sobre Educação Física Escolar e a cada momento surge mais uma proposta pedagógica, mais um projeto pedagógico, mais uma ideia de grupos representando Secretarias de Estado, ou Secretarias Municipais. Propostas diferentes em muitos sentidos, o que até seria saudável, mas, no entanto, entendo que as diferenças existem até mesmo na essência ou naquilo que deveria ser específico da Educação Física ${ }^{20}$ (p. 5).

Assim sendo, retomando o tema das práticas inovadoras em Educação Física Escolar, talvez seja importante interpor a questão da especificidade do componente curricular em relação a outras especificidades como, por exemplo, a especificidade da cultura escolar e dos diferentes níveis de escolarização. Num entendimento sistêmico, a escola se insere numa política educacional, os níveis de ensino se organizam de forma orgânica e de maneira interdependente 
e, finalmente, são os componentes curriculares os constructos culturais sistematizados que mediarão e viabilizarão as intencionalidades educativas de todo o sistema. No atual contexto histórico e político, em tempos de neoliberalismo vigoroso e reformas educacionais apressadas, muitos componentes curriculares estáo sendo questionados quanto à sua validade na perspectiva da escola da eficácia em detrimento da escola da cidadania. Em que pese as controvérsias e ambivalências do atual quadro, as escolas e seus agentes deverão efetuar um esforço de conjugar suas particularidades (experiências e práticas educativas) com as demandas e pressóes sociais/ políticas multilaterais. As áreas do conhecimento, bem como as tradiçóes do pensamento e da cultura que não tiverem certa "liga", mesmo a despeito de todos os protagonismos críticos e inventivos das práticas inovadoras, terão, como conjectura, dificuldades de subsistir no quadro mais geral da escolarização. Possivelmente, mesmo a despeito da necessidade e legitimidade de cada prática inovadora em cada contexto escolar, por mais relevante que sejam, essas mesmas podem ter sido necessárias em virtude de uma lacuna histórica da área, ou seja, da precariedade identitária dos conteúdos e saberes escolares. Coube aos docentes, de forma desafiadora e honrosa, a construção desses entendimentos e consubstanciálos como trabalho educativo no cotidiano escolar, muitas vezes por sua conta e risco.

Como especulação reflexiva, não seria devaneio supor que os professores e professoras tenham que "cobrir" a ausência de clareza sobre o objeto que se debruçam, sobre a especificidade dos saberes a ensinar pela Educaçáo Física, especialmente, quando nos ocupamos de um incomensurável objeto denominado cultura corporal de movimento constituído de temas e manifestaçóes (jogos, danças, lutas, brincadeiras, atividades circenses etc.) diferenciadas da própria Educação Física. Que critérios utilizamos para efetuarmos um corte epistemológico e curricular sobre um objeto de patente magnitude? Não podemos apostar, somente, na pretensão inventiva, personalista e voluntariosa dos nossos estimados e valorosos docentes. É uma demanda institucional/coletiva da Educação Física Escolar. Sim, parte substancial das respostas aos desafios da escolarização devem ser encontradas no trabalho dos professores e professoras. Contudo, as políticas públicas, as bases curriculares e os cursos de licenciaturas, não podem deixar o professorado sem os devidos parâmetros, sinalizaçóes e esclarecimentos relativos à especificidade das práticas do componente curricular em questáo, mesmo que esses mesmos educadores estejam imbuídos das suas responsabilidades, autonomias, atitudes críticas e competências inovadoras.

Enfim, arguindo de outro modo, qual seria o futuro de um componente ou área curricular, cuja orientação fica ancorada pela diversidade infinita do ímpeto criativo ("inovador") dos seus interlocutores? Desse modo, seríamos forçados a fazer uma pergunta impertinente: O que há de novo nas práticas inovadoras?

Independentemente das possíveis respostas, reforçamos que o chão da escola tem sentido os reflexos de uma política que desconsidera o conhecimento tácito do professor e seu saber emergente dos contextos constituídos. Mesmo assim, são esses esforços docentes e discentes que têm conferido os sentidos locais necessários para nutrir a educação corporal no seio do movimento escolar. Possivelmente, são esses protagonismos inovadores que desafiarão as "verdades" instituídas tanto pelas atuais políticas públicas de currículo e formação continuada de professores, como também, os saberes provenientes do "Homo Academicus".

\section{Abstract}

School Physical Education: discussing the innovative practice.

The objective of this essay is to analyze the notion of innovative pedagogical practice in School Physical Education, based on the exploration of the specialized literature. The announcements regarding innovative, renewing or "successful" pedagogical practices in School Physical Education have been conveyed in various academic and professional settings. As relevant aspect, the need to orient these educational practices epistemologically, in order to give identity to the curricular component.

KEYwords: School Physical Education; Curriculum; Didactics. 


\section{Referências}

1. Bracht V, González FJ. Educação física escolar. In: González FJ, Fensterseifer PE, organizadores. Dicionário crítico de educação física. Ijuí: Unijuí; 2014. p. 241-7.

2. Silva MS, Bracht V. Na pista de práticas e professores inovadores na educação física escolar. Rev Kinesis. 2012;30(1):80-94.

3. Silva RRD. Investir, inovar e empreender: uma nova gramática curricular para o Ensino Médio brasileiro? Currículo Sem Fronteiras. 2016;16(2):178-96.

4. Bracht V. Dilemas no cotidiano da Educação Física escolar: entre o desinvestimento e a inovação pedagógica. Salto Para Futuro. 2011;21(11):14-20.

5. Carlan P, Kunz E, Fensterseifer PE. O esporte como conteúdo da Educação Física escolar: estudo de caso de uma prática pedagógica “inovadora”. Movimento. 2012;18(4):55-75.

6. Faria BA, Bracht V, Machado TS, Moraes CEA, Almeida UR, Almeida FQ. Inovação pedagógica na educação física: o que aprender com práticas bem sucedidas? Agora Educacion Fisica Deporte. 2010;12(1):11-28.

7. González FJ. Atuação dos professores na Educação Física Escolar: entre o abandono do trabalho docente e a renovação pedagógica. In: Silva PCC, Gerez AG, Nascimento ANS, Silva BO, Loureiro FL, Almeida FQ, et al., organizadores. Territorialidade e diversidade regional no Brasil e na América Latina: suas conexôes com a Educação Física e com as Ciências do Esporte. Florianópolis: Tribo da Ilha. 2016;1:45-70.

8. Almeida FQ. Educação Física escolar e práticas pedagógicas inovadoras: uma revisão. Corpoconsciencia. 2017;21(3):7-16.

9. Farias US, Nogueira VA, Maldonado DT. Práticas pedagógicas inovadoras nas aulas de Educaçáo Física escolar: indícios de mudanças. Curitiba: CRV; 2017.

10. Correia WR. Educação Física escolar: desafiando a sua presumível imutabilidade. Rev Bras Educacao Fisica Esportes. 2014;28(4):691-700.

11. Vago TM. Início e fim do século XX: maneiras de fazer educação física na escola. Cad Cedes. 1999;19(48):30-51.

12. Sacristan JG, Gómez AIP, Rodríguez JBM, Santomé JT, Rasco FA, Méndez JMA. Educar por competências: o que há de novo? Porto Alegre: Artmed; 2011.

13. Messina G. Mudança e inovação educacional: notas para reflexão. Cad Pesquisa. 2001;114:225-33.

14. Pereira DRM, César DR. Inovação e abertura no discurso das práticas pedagógicas. Avaliacao. 2016;21(2):619-36.

15. González FJ, Fensterseifer PE. Entre o "não mais” e o "ainda não": pensando saídas do não-lugar da EF escolar I. Cad RBCE. 2009;1(1):9-24.

16. Maldonado DT, Vieira PBA, Freire ES, Sanches Neto L. Inovação pedagógica nas aulas de educação física da escola pública brasileira [Internet]. In: Seminário LOED - Avaliação da escola pública sob o viés da qualidade social. 2016 [citado $28 \mathrm{Fev}$ 2018]:75-83. Disponível em: https:/www.researchgate.net/publication/314426295_INOVACAO_PEDAGOGICA_NAS_ AULAS_DE_EDUCACAO_FISICA_DA_ESCOLA_PUBLICA_BRASILEIRA.

17. Fensterseifer PE, Silva MA. Ensaiando o "novo" em educação física escolar: a perspectiva de seus atores. Rev Bras Ciencias Esporte. 2011;33(1):119-34.

18. Caparroz FE, Bracht V. O Tempo e o lugar de uma didática da educaçáo física. Rev Bras Ciencias Esporte. 2007;28(2):21-37.

19. Tani G. Perspectivas para Educaçáo Física escolar. Rev Paulista Educ Fis. 1991;5(1-2):61-9.

20. Mariz de Oliveira JG. Educação Física escolar: construindo castelos de areia. Rev Paulista Educ Fis. 1991;5(1-2):5-11.

\begin{tabular}{r|r} 
ENDEREÇO & \\
Walter Roberto Correia & \\
Escola de Educação Física e Esporte - USP & Submetido: 02/07/2018 \\
Av. Prof. Mello Moraes, 65 - Cidade Universitária & Aceito: 05/07/2018 \\
05508-030 - São Paulo - SP - BRASIL & \\
e-mail: wr.correia@usp.br & \\
&
\end{tabular}


